\title{
Can fish suffer?: perspectives on sentience, pain, fear and stress
}

\author{
K.P. Chandroo, I.J.H. Duncan, R.D. Moccia* \\ Department of Animal and Poultry Sciences, University of Guelph, Guelph, Ont., Canada N1G 2W1
}

\begin{abstract}
In contrast to other major forms of livestock agriculture, there is a paucity of scientific information on the welfare of fish raised under intensive aquacultural conditions. This reflects an adherence to the belief that these animals have not evolved the salient biological characteristics that are hypothesised to permit sentience. In this review, we evaluate the scientific evidence for the existence of sentience in fish, and in particular, their ability to experience pain, fear and psychological stress. Teleost fish are considered to have marked differences in some aspects of brain structure and organization as compared to tetrapods, yet they simultaneously demonstrate functional similarities and a level of cognitive development suggestive of sentience. Anatomical, pharmacological and behavioural data suggest that affective states of pain, fear and stress are likely to be experienced by fish in similar ways as in tetrapods. This implies that fish have the capacity to suffer, and that welfare consideration for farmed fish should take these states into account. We suggest that the concept of animal welfare can be applied legitimately to fish. It is therefore appropriate to recognize and study the welfare of farmed fish. (C) 2004 Elsevier B.V. All rights reserved.
\end{abstract}

Keywords: Animal welfare; Aquaculture; Fish; Sentience; Pain; Fear; Stress; Suffering

\section{Introduction}

Finfish aquaculture is the production of any fish species, through artificial cultivation techniques, and embodies the primary objectives of increasing biomass and ensuring successful reproduction. Over the last decade, finfish aquaculture production has more than doubled worldwide, and is projected to become an increasingly significant source of animal protein worldwide (FAO, 2000). In contrast to other major forms of livestock agriculture, there is a paucity of scientific information on the welfare of fish raised under intensive aquacultural conditions. This indicates an adherence to the popular view that the neuro-anatomical

\footnotetext{
* Corresponding author. Tel.: +1-519-824-4120x56216; fax: +1-519-767-0573.

E-mail address: rmoccia@uoguelph.ca (R.D. Moccia).
} 
and physiological features of fish do not permit sentience. Although there has been a perceived need for an assessment of the welfare status of intensively cultured fish (Peters, 1990; Bernoth, 1991; Needham and Lehman, 1991; Lymbery, 1992; Kestin, 1994; Neukirch, 1994; FAWC, 1996; Spedding, 2000), the underlying basis of exactly how the concept of animal welfare relates to fish has remained unclear and largely unexamined in the scientific literature. Recent works pertaining to the question of conscious states in fish yield no consensus (Rose, 2002; Sneddon et al., 2003). In the present review, we evaluate the scientific evidence that may facilitate an understanding of how animal welfare concepts apply to farmed fish.

\section{Why should farmed fish receive welfare consideration?}

The welfare of an animal refers to its quality of life (Duncan and Fraser, 1997), a concept that is open to much debate among scientists because it is difficult to define in precise, scientific terms, and because it necessarily involves normative judgements about the meaning of quality. Nevertheless, a number of research approaches to the study of animal welfare have emerged (Duncan and Fraser, 1997; Fraser et al., 1997). Although a case for fish welfare could be reasonably argued within the scope of any one of the main animal welfare concepts, it is the approach put forward by Duncan (1996) that provides a conceptual framework to answer the question "why should fish receive welfare consideration or a welfare status?". In Duncan's approach, it is not necessarily the state of health or amount of stress that an animal has, that matters to its welfare, but the possession and state of a number of cognitive capacities (Duncan and Petherick, 1991; Curtis and Stricklin, 1991; Duncan, 1996). The cognitive capabilities in question are those which form the basis of sentience. Hence, sentience is a prerequisite to having a welfare status (Wood-Gush et al., 1981; Duncan, 1996). It follows that if fish are to be given welfare consideration, they must reasonably demonstrate the cognitive characteristics of sentient beings.

\section{Cognitive abilities of sentient animals}

The "simplest" of the cognitive processes that may characterize sentience involves being aware of internal and external stimuli (Duncan, 1996; Salzen, 1998). This cognitive ability has also been defined as conscious cognition (Århem and Liljenström, 1997), and, according to some authors, is dependent upon the development of primary consciousness (Lindahl, 1997; Edelman and Tononi, 2000). Primary consciousness can be defined as "the ability to generate a mental scene in which diverse information is integrated for the purpose of directing behaviour" (Edelman and Tononi, 2000). There are several good accounts of the emergence of conscious cognition and primary consciousness in evolutionary history (Humphrey, 1992; Århem and Liljenström, 1997; Lindahl, 1997).

"Motivational affective states" include a wide range of conscious experiences such as pain, fear, hunger, thirst and pleasure. They have long been recognised as adaptive products of natural selection (e.g. Romanes, 1884) and play an important role in the causation of some types of behaviour (Fraser and Duncan, 1998). These are also the states that are increasingly being used in animal welfare evaluations, with the absence of negative affective states and the 
presence of positive affective states being interpreted as a measure of good welfare (Duncan, 1996, 2002; Broom, 1998). Although these motivational affective states are subjective, i.e. they are only available to the subject experiencing them, nevertheless, it is possible to gain information about them through indirect evidence (Dawkins, 1993; Duncan, 1996, 2002; Dol et al., 1997; Griffin, 1998; Rolls, 2000).

The indirect evidence for conscious motivational affective states comes from a variety of sources including neuro-anatomy, neuro-physiology and behaviour, with an animal's behaviour probably being the best window into its subjective states (Duncan, 2002). When the nervous system of a species attains a sufficient level of complexity during evolution, it is believed that some types of behaviour become indicative of an animal's ability to form and act upon structured, internal neural representations of its internal and external environment (i.e. it develops primary consciousness) (Århem and Liljenström, 1997; Shettleworth, 2001).

Aspects of this cognitive ability can be shown experimentally by testing the hypothesis of whether learned information is retained by an animal as a procedural representation, or as a declarative representation (Heyes, 1993; Dickinson and Balleine, 1994). Procedural representations mediate stimulus-response behaviour. When an animal is using a procedural representation, it simply reacts to a stimulus without having awareness or comprehension about the consequences of its response (this does not mean, however, that the actual response itself cannot involve a conscious state). Declarative representations permit selective attention to internal and external stimuli, anticipation, expectation and goal-directed activity, allowing for increasingly flexible behaviour and adaptive responses (Århem and Liljenström, 1997; Eichenbaum, 1997; Lindahl, 1997). Thus, consciousness or sentience in animals is a phenomenon that may be inferred by examination of the cognitive abilities and neuroanatomical features that an animal may posses.

If it can be shown that species of farmed fish have neuroanatomical, behavioural and physiological attributes that characterize conscious cognition or motivational affective states, then there may be compelling evidence to suggest that fish can suffer. Teleost fish (e.g. Salmonidae) are considered to have marked differences in some aspects of brain structure and organization as compared to tetrapods (i.e. Class Amphibia, Reptilia, Aves, Mammalia), yet simultaneously demonstrate complex brain architecture and brain functions similar to those found in tetrapods (e.g. Nieuwenhuys, 1982; Lee and Bullock, 1984; Kálmán, 1998; Kotrschal et al., 1998; Anadón et al., 2002; Vonderschen et al., 2002; Wullimann and Rink, 2002). In addition, we suggest that there is a substantial body of scientific evidence demonstrating that species of fish used in aquaculture possess cognitive abilities consistent with the hypothesis that primary consciousness and conscious cognition evolved in fish species (whether it be homologous or homoplastic to the condition in tetrapods). The following discussion gives a selection of key examples illustrating the biological characteristics of fish that may suggest that they are sentient.

\section{Fish behaviour and internal representations}

Experiments designed to test whether or not some types of fish behaviour is governed by procedural or declarative representations per se are rare or non-existent. However, the experimental design of some fish behaviour studies, effectively allows for such a distinction 
to be made, or, whose results point to key behavioural features indicating the existence of primary consciousness. Topál and Csányi (1999) performed several experiments that were designed to test their "Interactive Learning Hypothesis". The Interactive Learning Hypothesis states that learning processes of fish may be based on internal representations formed as a consequence of paying active attention to and interacting with external stimuli, as well as the memories of former experiences which may be combined and transformed so that new knowledge may be constructed to direct behaviour. In one such experiment, Topál and Csányi (1999) showed that paradise fish (Macropodus opercularis) could associate distinct, unpaired stimuli (i.e. stimuli not related by causal relevance, temporal contiguity or the correlation of events) and demonstrate anticipatory or predictive behaviour as a result of the association. Paradise fish were pre-exposed to a shuttle tank (a single tank divided into a light and dark compartment, in which the fish had access to each compartment via a centrally located gate). Twenty-four hours after pre-exposure, a training session occurred where fish were placed in the light compartment, and were given an electric shock whenever they entered the dark compartment. Mild electric shocks administered to fish in the dark compartment of the shuttle tank did not become aversive; instead, they caused fish to explore the tank. Topál and Csányi (1999) went on to show that exploratory behaviour demonstrated by mildly shocked fish could be extinguished or replaced by avoidance behaviour depending upon the acquisition of earlier memories of their environment, as well as the presentation of other, unpaired stimuli. Other experiments performed by Topál and Csányi (1999) showed that their results could not be explained by traditional associative theory (e.g. second order conditioning), but rather, learning demonstrated by paradise fish was indicative of an actual capability for mental construction that could direct their behaviour in flexible and adaptive ways. From a behavioural perspective, the empirical results of Topál and Csányi (1999) clearly demonstrate the key characteristics of the ability to form declarative representations.

Experimental examination of fish communication indicates that they can extract information from external events in which they are not involved via observational learning, and subsequently use that information to direct their future behaviour in flexible and adaptive ways. In these experiments, the behaviour of fish acquiring information via observational learning is not manifested as trial and error learning to a new salient aspect of the environment, but may be explained by the hypothesis that fish make predictions of the outcome of a behavioural act. This suggests that fish may use declarative representations under these circumstances. Visually mediated observational learning is a complex phenomenon, and ranges from learning about stimuli, objects or events in the environment, to conspecific behaviour responses (Heyes, 1993). Observational learning may also be involved in goal-directed behaviour or some other form of simple, conscious reasoning (Heyes, 1993). Reports of observational learning in fish are reviewed in Kieffer and Colgan (1992).

McGregor et al. (2001) demonstrated the capability for observational learning and individual recognition in the Siamese Fighting fish (Betta splendens). Male Fighting fish allowed to observe a pair of males involved in an aggressive interaction, can gather information on the relative fighting ability between individuals, and use that information to direct their behaviour in subsequent confrontations with those previewed individuals (McGregor et al., 2001). Since, in these experiments, the "winner-loser" effect, environmental history, competitive ability and colour brightness of the fish were controlled, it was determined that 
it was the memory of an individual's relative fighting ability (related to the level of aggressiveness) that was used to direct the observer's future behaviour. Oliveira et al. (1998) showed that observing fish were less motivated to engage in a confrontation with an animal that they had previously seen win a dyad interaction, and more motivated to confront a fish they had seen lose. However, McGregor et al. (2001) designed an apparatus where it was possible for the observer to watch an interaction in which the relative fighting ability between the winner and loser was less or non-distinct; in this case, both combatants could appear to show behaviour indicating that they had won the contest (i.e. increased levels of aggression). Observing fish later paired with the most aggressive, winning previewed fish were more willing to engage in a confrontation. Since observing fish could extract and use information from external events of which they were not involved, and their behavioural responses to previewed fish was sensitive not only to changes in the level of aggressiveness displayed by previewed fish, but also to the outcome of a conflict, then it seems unlikely that fighting ability is remembered as a procedural representation. If information on an individual's fighting ability was retained as a procedural representation, then we would expect that, (a) observing fish should need direct trial-and-error experience with conspecifics in order to alter their fighting behaviour during future conflicts, and (b) an observing fish should alter its response to previewed fish in a stimulus-response manner. That is, fish should be more likely to engage losers (less aggressive fish) and not winners (more aggressive fish) of interactions they have direct experience with. Further investigation is necessary to demonstrate unequivocally that the memories of an individual's fighting ability are being retained as a declarative representation. It has also been shown that, female Siamese Fighting fish could gather information about interacting males, and subsequently use that information to direct their behaviour during mate choice (Doutrelant and McGregor, 2000). Females appeared to choose males not just on the basis of their relative fighting ability, but also on the memory of additional cues that were informative of the context of the aggressive male act.

Individual recognition and the ability to assess fighting skill through observation are not limited to Fighting fish, and have been demonstrated in other species of cultured fish (e.g. Morris et al., 1995; Höjesjo et al., 1998). Rainbow trout are aggressive animals that, under some circumstances, fight each other to form and maintain dominance hierarchies or territories (Abbott and Dill, 1985). Individual rainbow trout possess the cognitive ability to recognize previous opponents, and to modify their own fighting behaviour accordingly (Johnsson, 1997). In addition, rainbow trout can assess the individual-specific fighting ability of future opponents. Johnsson and Akerman (1998) tested the hypothesis that a trout (the observer) could, via observational learning, assess the likelihood of winning a conflict with previewed individuals involved in a dyadic contest, and alter it's strategy during subsequent contests with those individuals. An observer viewed a dyadic trial in which a dominance-subordinate relationship between the combatants was established. In a subsequent contest where the dominant fish was paired with the observer, it was found that the fighting strategies of the observer were altered, regardless of whether the observer eventually became dominant or submissive to the previewed fish. Fish tested in Johnsson and Åkerman (1998) were sized matched to standardize for fighting ability, and olfactory recognition was not a significant factor in influencing their results. This suggests that the observer could assess its future probability of winning a conflict by comparing previously 
obtained knowledge of its own fighting ability with that of a previewed individual. This also suggests that the memories relating to fighting ability may be stored as declarative representations, although additional studies would be needed to confirm that hypothesis. Fish appeared to use memories of some aspects of their own fighting ability, as well the memories of a previewed individual's fighting ability in an adaptive and flexible way, in order to direct their future behaviour when fighting with individuals that they had no direct experience with.

Aggressive species of farmed fish may also communicate with each other during contests. In fighting contests between Atlantic salmon (Salmo salar), a fish can suddenly change its body colour, which indicates submission to an opponent (O'Connor et al., 1999). Darkening of body colour usually causes the winner of the bout to reduce its aggression towards the darkened fish (O'Connor et al., 1999). During a fighting contest, body darkening is not considered to be a general indicator of physiological stress (O'Connor et al., 1999). Furthermore, it has been suggested that body darkening in subordinate Atlantic salmon occurs upon recognition of dominant individuals in order to avert escalated fights (O'Connor et al., 2000). Subordinate Arctic charr (Salvelinus alpinus) may also use skin darkening as a submissive social signal (Höglund et al., 2000). In the preceding examples, there was evidence that fish could remember, recognize and interpret the fighting skills of future opponents in order to assess their own probability of winning a future conflict, as well as signal their motivational state to familiar conspecifics. Most of these behavioural traits involve visually mediated observational learning, and may be indicative that fish can retain memories as declarative representations. These examples form a preliminary basis for suggesting that primary consciousness and conscious cognition exist in fish.

\section{Motivational affective states}

Motivational affective states are biological adaptations that motivate specific behaviour, especially in situations where a flexible or learned response is more adaptive than a rigid or reflexive one (Fraser and Duncan, 1998). Awareness of internal and external states is probably not an all or none phenomenon, but rather is "graded" (Salzen, 1998) or limited to a range of subject matter appropriate for the animal's ecology (Griffin, 1998). The question of what are the fundamental underlying neural mechanisms of affect is highly debatable (Rolls, 2000). However, specific brain structures and neural systems have been associated with emotions and motivated behaviour in tetrapods. The limbic system is a collection of brain structures which has some functions in aspects of emotional behaviour, memory, and learning (Kötter and Meyer, 1992; Ono et al., 2000). The involvement of the limbic system, although commonly invoked, is controversial with respect to explanations of how emotions might be generated by its functioning. However, it remains useful from the perspective of demonstrating that a significant quantity of research supports the view that emotions involve relatively primitive brain circuits that are conserved through evolution (LeDoux, 2000). In addition to the limbic system, specific dopaminergic neural systems are involved in some types of affective and motivational processes (Fibiger and Phillips, 1986). Despite differences in ontogeny, there is a growing body of anatomical, behavioural, and pharmacological 
evidence to suggest that the brain structures and neural systems associated with motivational affective states in tetrapods are present in fish (Ito and Kishida, 1978; Munro and Dodd, 1983; Kálmán, 1998; Butler, 2000).

\subsection{Limbic system}

Since the behavioural effects of ablation of the telencephalon in fish resemble results from lesion experiments on the mammalian limbic system (Portavella et al., 2002), the fish telencephalon, along with other brain structures, has been hypothesised to be functionally homologous to limbic structures found in tetrapods (Ohnishi, 1997; Mok and Munro, 1998). The limbic system of tetrapods may consist of the hippocampus, amygdala, hypothalamus, habenula and mammillary bodies (Kötter and Meyer, 1992). The hippocampus of tetrapods is involved in memory and learning of spatial relationships. The ability to form declarative representations is also dependent upon the hippocampus (Eichenbaum, 1997). Spatial and associative learning in goldfish are affected by telencephalon ablation in similar ways to hippocampal lesions in mammals and birds, suggesting that regions of the telencephalon are homologous to the hippocampus of tetrapods (Salas et al., 1996a,b; López et al., 2000a,b; Vargas et al., 2000). Furthermore, hippocampal regions of the fish telencephalon have been shown to function as a map-like relational spatial memory system, and play a crucial role in the use of flexible representations (Rodríguez et al., 2002a,b). These data also corroborate the behavioural evidence presented earlier which suggests that fish may have declarative representations. The amygdala of tetrapods contributes to olfactory input processing, arousal and emotions, such as fear (Maren, 2001). In fish, an amygdaloid complex exists and is located in the telencephalon (Munro and Dodd, 1983; Bradford, 1995; Yoshimoto et al., 1998; Carruth et al., 2000). Lesions or electrical stimulation of the amygdalar region in fish produces changes in aggression similar to those observed following amygdalar lesions or stimulation in tetrapods (Bradford, 1995; Portavella et al., 2002). The hypothalamus of tetrapods is involved in the integration and control of a variety of autonomic functions, sexual behaviour and emotions (Petrovich et al., 2001). The hypothalamus of fish is well studied with respect to its anatomy (Munro and Dodd, 1983) and its involvement in endocrine functions (Sumpter, 1997). As in other vertebrates, the hypothalamus of fish is involved in sexual and other social behaviour and is responsible for integrating a variety of environmental and internal signals, including those (internal signals) originating from the telencephalic areas implicated in emotional learning (Fox et al., 1997; Folgueira et al., 2002; Portavella et al., 2002). The mammillary bodies and habenulae of tetrapods function in olfaction. Mammillary bodies may be represented in the fish brain, although their structural and functional limits are not clear (Sawai et al., 2000). The habenulae are better studied in fish (Bradford and Northcutt, 1983; Corrêa et al., 1998), and may contribute to several forebrain pathways, including those involved in olfaction (Yañez and Anadón, 1996).

\subsection{Dopaminergic systems}

Mesolimbic and mesostriatal dopaminergic neurons facilitate normal functioning of forebrain and other neuronal systems (Le Moal and Simon, 1991). Since mesolimbic 
dopaminergic neurons project into the limbic system (Le Moal and Simon, 1991) and mediate learning and reward mechanisms (Fibiger and Phillips, 1986), mesolimbic neurons have been implicated in the control and expression of behaviour that results from emotion. There is evidence to suggest that dopaminergic innervation of the fish telencephalon mediates motivational states and behaviour in ways similar to tetrapods.

A reward is anything for which an animal will work. Reward behaviour observed in tetrapods, is hypothesised to be related to an emotional state (Rolls, 2000), and can be experimentally manipulated through use of psychotropic drugs. Since administration of dopaminergic agonists (e.g. amphetamine, apomorphine) produces reward behaviour in both mammals and fish, it has been hypothesised that central reward mechanisms of fish are similar to those found in other vertebrates (Lett and Grant, 1989; Mattioli et al., 1995). This hypothesis is further supported by pharmacological studies investigating the effects of substance $\mathrm{P}$ on vertebrate behaviour. In addition to pain mediation, the neuropeptide substance $\mathrm{P}$ is involved in learning, memory and reward processes in mammals, and its effects may be mediated through dopaminergic systems (Mattioli et al., 1995). In fish, as in mammals, dopaminergic cell bodies can be located at similar brain regions where substance P terminals are found (Mattioli et al., 1997). Using an appetitively motivated learning task, Mattioli et al. (1997) demonstrated that substance P treatment has a similar effect on the memory and reward system of goldfish, and that these effects are also mediated by dopaminergic systems. In addition, Santangelo et al. (2001) showed that substance P improved learning and memory processes of goldfish during avoidance testing, and implicated ventral telencephalic structures in mediating such processes. In fish, dopaminergic agonists may influence behaviour (Mok and Munro, 1998), and have been implicated in mesolimbic regulation of aggression and fear. Munro (1986) showed that intercranial injections of D-amphetamine or immersion in apomorphine inhibited aggression in a teleost fish, Aequidens pulcher. Furthermore, apomorphine inhibits aggression in A. pulcher in a dose-dependant fashion; this is consistent with observations for mammals treated with apomorphine (Munro, 1986). Investigations of apomorphine treatment on fish behaviour have also lead researchers to suggest that telencephalic dopaminergic neurons mediate fear responses of fish (Oreochromis niloticus, O. mossambicus) to novel environments (Mok and Munro, 1998). Meperidine derivative (MPTP) causes a Parkinsonian syndrome in humans and primates by altering or destroying mesostriatal dopaminergic neurons (Pollard et al., 1996). MPTP administered to goldfish also elicits a Parkinsonian syndrome, consisting of marked behavioural and neurochemical changes in the telencephalon that closely parallel observations in tetrapods (Goping et al., 1995; Pollard et al., 1996). Ocular abnormalities that occur in Parkinson's syndrome can also be induced in fish by altering dopaminergic neurotransmission (Dietrich et al., 2002).

In summary, the anatomical, physiological and behavioural features of fish show evidence for having functional, homologous limbic and dopaminergic structures as present in tetrapods (Munro and Dodd, 1983; Rink and Wullimann, 2001; Wullimann and Rink, 2002). The presence of these neural systems in fish, along with similar declarative type memory systems suggest that modern fish and tetrapods have inherited those traits from a common ancestor during vertebrate evolution. Some of these traits may have been retained without extreme functional modification, and there is research available to support the view that emotions involve relatively primitive brain circuits that are conserved through evolution. 
Therefore, it is reasonable to suggest that motivational affective states could have developed at some level of fish evolution (e.g. the Actinopterygii).

\section{Pain and the telencephalon}

The information pertaining to pain in fish is limited, but a sufficient amount of data has emerged so that hypotheses pertaining to the phylogenetic origin of pain perception in vertebrates are possible to generate. The limited quantity of data, however, fuels the perception that conclusions about the existence of pain perception in fish are entirely subjective. After a preliminary examination of the neurological, pharmacological and behavioural evidence of pain perception in fish, Gregory (1999) restates the problem as "the appropriate question appears not to be do fish feel pain?, but rather, what types of pain do fish experience?". Based on the information that we present here, we suggest that pain in fish may be experienced in ways similar to tetrapods.

\subsection{Peripheral detection of noxious stimuli: nociceptors}

The receptors, neuronal pathways and specific transmitter molecules that convey information about pain in vertebrates is collectively termed the nociceptive system (Zieglgänsberger, 1986). In tetrapods, nociceptors are the peripheral sensory nerve endings specialised to signal and encode tissue damaging stimuli (Zimmermann, 1986). Nociceptor fibres may be polymodal (i.e. respond to multiple noxious stimuli) myelinated A-delta and unmyelinated C fibres (Besson, 1999). In human beings, stimulation of A-delta fibres eventually leads to a prickling type of pain, whereas stimulation of $\mathrm{C}$ fibres produces a burning or dull pain (Willis and Westlund, 1997). Anatomical and physiological studies have confirmed the existence of both A-delta and $\mathrm{C}$ nociceptor fibres in rainbow trout. As in tetrapods, A-delta and C fibres in the trout trigeminal nerve are polymodal, slowly adapting receptors that are activated by mechanical, thermal and chemical stimuli (Sneddon, 2002; Sneddon et al., 2003). In addition to more evolved species of fish, anatomical and physiological studies of primitive fish (Lampreys, Petromyzon marinus, Ichthyomzon unicuspis) have confirmed the existence of functional nociceptor nerve fibres. In these studies, destructive stimuli (pinching, puncturing, burning) applied to the skin resulted in electrophysiological activity of trigeminal ganglia innervating the fish's head (Matthews and Wickelgren, 1978), and dorsal cells (a class of primary sensory neuron) in the fish's spinal cord and brain (Martin and Wickelgren, 1971; Rovainen and Yan, 1985). Dorsal cells of the lamprey spinal cord are thought to be similar to some types of nociceptive neurons found in tetrapods (Martin and Wickelgren, 1971); similar cells are also found in teleost fish (Finger and Rovainen, 1982). However, the electrophysiological characteristics that distinguish nociceptive-specific from pressure-specific dorsal cells in the spinal cord of the lamprey are controversial (Christenson et al., 1988). Additional research is needed before comparisons of lamprey nociceptive-specific dorsal cells can be made with tetrapod nociceptors. Other peripheral nerve fibres may convey nociception in fish. Based upon anatomical and electrophysiological evidence, as well as the presence of pain-mediating neurotransmitters, both Christenson et al. (1988) and Martin and Wickelgren (1971) implicate lamprey dorsal root ganglion cells as having nociceptive functions. 


\subsection{Central integration of nociceptive signals: spinal pathways}

In tetrapods, central nervous system (CNS) processing of peripheral nociceptive information begins at the level of the spinal cord or brainstem. Neuronal networks within the spinal cord modulate and transmit nociceptive signals to various sites within the brain, and to other spinal neurons (e.g. flexor motor neurons; Willis and Westlund, 1997). In general, both fish and tetrapods show similar organization of major spinal pathways (i.e. the dorsal column and spinal lemniscus systems) that transmit neural signals within the spinal cord to the brain (Ronan and Northcutt, 1990). Within these major spinal pathways, several nerve fiber tracts may be involved in the transmission of nociceptive information in tetrapods. These include spinothalamic, spinomesencephalic, spinoreticular and spinolimbic tracts (Willis and Westlund, 1997; Chapman and Nakamura, 1999). Depending on the species, one or more of these spinal tracts have been identified in fish (Ebbesson and Hodde, 1981; Murakami and Ito, 1985; Ronan and Northcutt, 1990; Finger, 2000). Although mammals exhibit more recently evolved spinal tracts that carry nociceptive signals to the brain (i.e. the neospinothalamic tract), phylogenetically older tract systems, as found in "lower" vertebrates, still function in mammalian pain perception (Kevetter and Willis, 1984). This suggests that spinal pathways that transmit and modulate nociceptive signals to the brain are phylogenetically old and are not restricted to the tetrapods. In teleost fish, trigeminal nerve afferents implicated in nociception enter the brainstem and project to brain nuclei (Nieuwenhuys and Pouwels, 1983; Puzdrowski, 1988). Several peptides that may transmit and modulate nociceptive signals may be found within these trigeminal brain nuclei (Cuadrado et al., 1994). In addition, research has demonstrated that autonomic nervous system and behavioural responses of teleost fish to noxious stimuli are specifically indicative of the detection (via the trigeminal or other cutaneous nerves) and transmission of nociceptive signals to brain centres (Ide and Hoffmann, 2002; Sneddon et al., 2003). In lamprey, sensory inputs into the spinal cord (e.g. via dorsal cells) can be transmitted to the brain through relay neurons (Buchanan, 2001) and are facilitated or inhibited by certain neuropeptides that are known to modify nociception in mammals (Ullström et al., 1999). The type and location of neuropeptides in the spinal cord of the lamprey also show strong homologies to that of other tetrapods (Ullström et al., 1999).

\subsection{Central integration of nociceptive signals: biochemical mediation}

The preliminary biochemical evidence for pain perception in fish also suggests that putative pain pathways and the biochemical mediation of nociception in fish are in some ways similar to the tetrapods. Substance $\mathrm{P}$ is a unadecapeptide found in a variety of animal tissues, and is known to be involved in the transmission and modulation of pain signals in tetrapods (Zieglgänsberger, 1986; Commons and Valentino, 2002). Immunohistochemical analysis of substance P distribution in the brain of the teleost fish Apteronotus leptorhynchus reveals trigeminal nerve fiber organization suggestive of a pain-transmission pathway involving a substance P-like peptide (Weld and Maler, 1992). FMRFamide is a peptide neurotransmitter found in the brain centers of tetrapods, and its function is closely associated with analgesic and aversive responses. FMRFamide is also found in homologous brain centers of trout, suggesting that it may also play a similar role in fish (Castro et al., 
2001). In mammals, adrenocorticotropin may be released from the pituitary gland when noxious stimuli are encountered (Chapman and Nakamura, 1999). Endogenous opioids (morphine-like substances) are also produced in tetrapods, which can suppress the intensity of pain experienced (Zieglgänsberger, 1986). A number of studies have shown that the nervous systems of teleost fish also produce chemical compounds related to adrenocorticotropic hormone and pain-mediating opiates (Ng and Chan, 1990; Vecino et al., 1992; Danielson et al., 2001). Jansen and Green (1970) and Ehrensing et al. (1982) demonstrated that analgesia could be achieved in goldfish (Carassius auratus) subjected to electric shocks by adding morphine to the tank water. Similarly, Chervova (1997) found that it was possible to modulate pain-induced behaviour of rainbow trout using opiate and non-opiate analgesics. Using opiate antagonists, Ehrensing et al. (1982) found that morphine analgesia in goldfish could be blocked through modes of action similar to those in tetrapods. In addition, it has been reported that at least six different protein binding sites, which may act as receptors for pain modulating molecules, are present in teleost fish (Stoskopf, 1994). In zebrafish (Danio rerio), the distribution and type of opioid receptors in the CNS supports a sensory or analgesic role for those receptors, and further suggests that some nociceptive pathways have been conserved throughout vertebrate evolution (Porteros et al., 1999). Expression of $\delta$-opioid receptors in zebrafish has been localised to limbic structures, as well as to other brain structures that have been implicated in pain mediation via ablation studies (Porteros et al., 1999). Sneddon (2003), demonstrated a morphine-induced reduction in pain-related behaviours as well as opercular beat rate in rainbow trout subjected to noxious stimuli. The author concluded that morphine acts as an analgesic in trout, and that the potential exists for both pain perception and response in fish that are not simply reflexive in nature.

\subsection{Nociception, the telencephalon and pain perception}

Conscious, subjective experience is an intrinsic component of pain (i.e. feeling pain) in humans and higher vertebrates (Rose and Adams, 1989). It is generally accepted that all conscious processes, including the perception of pain involves neural pathways that connect to various forebrain structures, including the cerebral cortex (Willis and Westlund, 1997). All vertebrate animals develop a forebrain (i.e. telencephalon and diencephalon brain regions). The pallium is a general term describing the grey matter that covers the telencephalon. Over the course of evolution, the pallium has thickened to various extents in different classes of vertebrates, and consists of a laminated structure in mammals, the cerebral cortex (Striedter, 1997). Among other functions, a laminated cerebral cortex leads to computational advantages with respect to sensory processing and motor functions (Striedter, 1997). Although the pallium of modern fish is unlaminated, (albeit lamination of pallial areas may be found in some fish species; Wicht and Northcutt, 1998), there is growing evidence to suggest that it has developed into a highly differentiated structure with respect to the processing of sensory information, and exhibits fundamental features that have been conserved throughout pallial evolution (Echteler and Saidel, 1981; Davis and Kassel, 1983; Bradford, 1995). The telencephalon of fish (pallial and sub-pallial structures) receive extensive neural projections from the thalamus and other specialised relay nuclei (Ito et al., 1986; Zupanc, 1997), and discrete pallial regions have been shown to be involved in the processing of somatosensory (e.g. possibly nociception via the trigeminal nerve; Ito et al., 1986), visual (Saidel et al., 
2001), gustatory (Yoshimoto et al., 1998), olfactory (Laberge and Hara, 2001), acoustic communication (Goodson and Bass, 2002) and other sensory modalities (Prechtl et al., 1998). In addition, the fish telencephalon may mediate sensory integration and executive functions analogous to those of the tetrapod telencephalon. Such integrative or executive functions of the fish telencephalon include the regulation of avoidance learning (Overmier and Hollis, 1990), habituation (Rooney and Laming, 1988), general arousal and social behaviour (Rooney and Laming, 1988; Overmier and Hollis, 1990; Riedel, 1998), as well as motivation and emotional learning (Portavella et al., 2002). Since the telencephalon processes somatosensory input and plays an integrative role in the avoidance responses of fish to noxious stimuli, it is probable that nociceptive signals (as well as other senses) in fish are not limited to initiating reflexes via the spinal cord or brainstem, but are also relayed to pallial and sub-pallial structures. The mechanisms by which pallial, sub-pallial and other brain regions generate consciousness, for any vertebrate animal, is the subject of intense debate and number of working hypotheses (Searle, 2000; Dehaene and Naccache, 2001; Dennett, 2001). Traditionally, it was thought that neurons with a particular anatomical location or biochemical feature (e.g. the neocortex or the reticular activating system) were somehow made distinct from other, seemingly identical neurons, so that their activity was responsible for consciousness (Tononi and Edelman, 1998). Dissatisfaction with this traditional view, and the acquisition of new data via brain imaging technology have fostered new mainstream approaches to the study of consciousness (Tononi and Edelman, 1998; Dennett, 2001; Baars, 2002). A fundamental tenet among these hypotheses is that the neural basis of consciousness involves widespread integration of differentiated pallial and sub-pallial neuronal populations within the brain (Baars, 2002). Since the cytoarchitecture of the fish brain is one that permits integration of differentiated pallial and sub-pallial regions (Cerdá-Reverter et al., 2001; Saidel et al., 2001; Wullimann and Rink, 2002), it is reasonable to suggest that modern hypotheses pertaining to the neural basis of consciousness may apply to fish.

As cognition and emotion appear to exist in a reciprocal relationship in humans (Chapman and Nakamura, 1999), pain perception in animals is commonly elucidated through the learning abilities of the animal (with respect to noxious stimuli), and through brain ablation experiments (Kitchell and Guinan, 1990). In general, teleost fish show learning abilities that are similar to those of other vertebrates that are presumed to experience pain (Overmier and Hollis, 1983). Briefly, learning in teleost fish can encompass non-associative processes (i.e. habituation, sensitisation, pseudoconditioning), associative processes (classical conditioning, operant conditioning, avoidance learning), integrative processes (transfer of control, successive reversal learning) and interactive learning processes (Savage, 1980; Overmier and Hollis, 1983; Topál and Csányi, 1999). Most of those learning processes can be facilitated by noxious stimuli, such as electric shocks, and are modulated by telencephalon ablation. With experience, fish can learn to avoid situations or locations where they have experienced noxious stimuli which are expected to produce pain (Overmier and Hollis, 1983). Rainbow trout may, through experience, associate an approaching conspecific with the physical consequences of receiving a nip that normally follows such an approach, and learn to retreat (Pitcher, 1993; Øverli et al., 1998). Fish also may actively avoid environments that were once preferred or rewarding (food liberating) if a noxious stimulus is introduced there (Overmier and Hollis, 1983; Piront and Schmidt, 1988). Fish may interpret tactile sensations as positive or negative; ectoparasites that irritate the skin and gills of Atlantic 
salmon cause them to initiate a leaping behaviour, apparently in an attempt to rid themselves of the irritation (Furevik et al., 1993). Fish may also solicit the attention of wrasses (cleaner fish that remove parasites from the bodies of other fish), suggesting that they find this tactile stimulation positive (Losey and Margules, 1974). Topál and Csányi (1999) found that the behavioural response of paradise fish to electric shocks significantly changed with shock intensity, as well as to the presence of other salient objects in their environment. While low intensity shocks stimulated exploratory activity (presumably to identify the source of the noxious stimuli), high intensity shocks elicited a passive defense or facilitated avoidance learning. Furthermore, if low intensity shocks (that initially caused exploratory behaviour) were administered to paradise fish in the presence of a harmless goldfish, exploration behaviour diminished and avoidance learning was detected (Csanyi, 1986; Topál and Csányi, 1999). The behavioural response of paradise fish to changes in intensity of punishment parallels that of rodents (Fanselow and Lester, 1988), and also suggests that noxious stimuli in these fish may be subject to cognitive processes that incorporate declarative representations. Zerbolio and Royalty (1983) designed a complex avoidance learning task in which goldfish were required to learn the relationship between signals (matching or oddity) in order to avoid being shocked, rather than simply learning which specific signals were paired with a shock. That fish were able to learn matching and oddity discriminations among a variety of signals in order to avoid being shocked suggests that such learning occurs at the conceptual level. Other avoidance learning studies in fish have been reviewed by Overmier and Hollis (1990), who also suggest that fish have the ability to construct cognitive representations of noxious events and are able to form expectancies of the noxious stimuli as a result. In summary, it is becoming clear that fish have a capacity to detect, conceptualize and subsequently respond to nociceptive stimuli. From a neuroanatomical perspective, it would also appear that modern hypotheses pertaining to the neural basis of consciousness include, rather than exclude, fish species. Therefore, it is conceivable that nociception (and other senses) in fish is consciously experienced, and is responsible for motivated behaviour.

\section{Fear and anxiety}

Fear may be defined as a psychophysiological response to perceived danger, and is a phenomenon which acts as a powerful motivator to evade perceived threats (Jones, 1997). Fear in fish has been characterised through branchial responses, alarm pheromone-initiated responses and aversive behavioural reactions. Fearful responses of fish to noxious or startling stimuli, which are manifested as vigorous, rapid escape manoeuvres are collectively defined as fast-start responses. In tetrapods, Pavlovian fear conditioning is considered to be an integral component of defensive behaviour, and has been hypothesised to involve declarative neural representations requiring amygdaloid and hippocampal brain region involvement (Maren, 2001). The neurobehavioural basis for Pavlovian fear conditioning in fish, as elucidated through branchial or alarm responses, appears also to be dependent upon cognitive mechanisms and homologous brain regions similar to those of tetrapods. For example, in goldfish, fear responses to an imminent electric shock can be blocked by intracranial administration of a brain $N$-methyl-D-aspartic acid (NMDA) receptor antagonist 
(an anterograde memory blocker) (Davis and Klinger, 1994). In tetrapods, intra-amygdaloid infusions of NMDA antagonists may also prevent acquisition of Pavlovian fear conditioning (Maren, 2001). In some fish species, fear and anxiety-like responses may be elicited via an alarm substance pheromone that is exuded from injured skin (Smith, 1992). Although the pheromone-initiated fright response is innate, Hall and Suboski (1995) demonstrated that control over the inducement of fright behaviour could be transferred, through associative learning processes, from the pheromone to innocuous visual or olfactory stimuli. In addition, fear responses to the alarm pheromone diminish when fish are treated with anti-anxiety drugs that bind to specific benzodiazepine receptors in their brain (Rehnberg et al., 1989). Fish, as well as rodents, also show increased exploratory and foraging behaviour in novel, anxiogenic environments when treated with benzodiazepine drugs (Rehnberg et al., 1989). Furthermore, Wisenden and Smith (1998) showed that fish adjust their synthesis of alarm pheromone based upon the level of perceived environmental risk. These findings suggest that states of fear and anxiety in fish are mediated by limbic neural systems.

The fast-start response of fish to noxious or startling stimuli is characterised by a highenergy swimming burst, either starting from rest or imposed upon periods of steady swimming (Domenici and Blake, 1997). The actual response itself may be classified as a fixed action pattern (Eaton and Nissanov, 1985) which is triggered by the firing of a pair of large neurons located in the brain stem (Eaton et al., 1981). These neurons receive a rich supply of connections from sensory and integrative centers in the brain, and not surprisingly, fast-starts are initially dependent on sensory information which allows the fish to coordinate the trajectory of its response in relation to the stimulus (Roberts, 1992; Eaton et al., 2001). Therefore, although the fast-start response itself is a fixed action pattern, the context in which it is elicited by a fish varies. Fast-starts are used by fish in social interactions, during feeding behaviour, to escape predators, and for predatory strikes (Domenici and Blake, 1997). This opens the possibility that under certain conditions, there is likely to be a motivational basis for performing fast-starts. For example, Canfield and Rose (1993) demonstrated that feeding manoeuvres (capturing of a cricket) in goldfish incorporated fast-starts. Since the motivation for feeding is different from that of predator avoidance, the authors suggested that higher order neural processes may modulate sensory activation of the neurons which invoke the fast-starts. Canfield and Rose (1993) also suggested that there may be a voluntary component for the fast-start activation within a feeding context. Those suggestions are supported by the finding that alternative neural pathways that invoke fast-starts do exist (Eaton et al., 1982; Zottoli et al., 1999). Other studies have suggested that motivation may play a role in determining the fast-start response of fish when avoiding predators. Webb (1986) observed that fast-start responses of fish chased by predators were up to $15 \%$ quicker than when predators attacked but did not give chase. Further evidence for the existence of a motivational component in fast-start reactions, with particular reference to fear, were demonstrated in experiments performed by Cantalupo et al. (1995). Using the teleost mosquitofish, Girardinus falcatus, the investigators measured the direction of turning during an escape response evoked by a simulated predator. The test apparatus consisted of a rectangular tank in which a predator shape could be rapidly introduced and viewed by the fish through a transparent side of the tank. The simulated predator was presented only when the fish swam across the median portion of the tank, in a central position where the fish's central axis was perpendicular to the predator. Upon presentation of the predator, the 
fish would perform an escape response, either turning left or right, away from the predator. There are two findings of this study which are relevant to motivation and fear in fish. First, it was noticed by the investigators that with repeated testing of the same animal, the fish tended to avoid the centre of the tank where the stimulus presentation would occur. If the fish happened to swim in the tank centre, it tended to zig-zag rapidly (Bisazza et al., 1998). It therefore appears that the fish developed an active strategy to avoid an encounter with the stimulus. It is interesting to note that the learned association of fear with a particular position in the tank may require hippocampal involvement; similar mechanisms by which the hippocampal formation assembles contextual representations and transmits them to the amygdala for associative learning has been demonstrated in tetrapods (Maren, 2001). Since the zig-zag swimming and the escape response were used by the fish to prevent presentations or to remove itself from a stimulus previously perceived as negative, it is reasonable to conclude that the fish could anticipate the frightening stimulus, and the escape response was in part motivated by an affective state of fear. The second point of interest in this study relates to the direction (left or right) of the escape response shown by the test fish. The fish tested by Cantalupo et al. (1995) showed a tendency to escape to the right, but after repeated predator occurrences, were biased to escape to the left. The authors speculated that the change in escape direction from right to left was related to the way that the fish categorised the predator stimulus. In animals with laterally placed eyes, as in most fish species, the visual scenes on the right and left sides may evoke different types of behaviour, as a result of differing modes of analysis of perceptual information carried out by the left and right sides of the brain (Bisazza et al., 1997a,b, 1999; Facchin et al., 1999). Cantalupo et al. (1995) reasoned that an initial escape to the right would keep the fishes left eye in contact with the predator stimulus, possibly because of the involvement of the right-sided structures of the brain in response to fright. The different involvement of the right and left sides of the brain (i.e. lateralisation) has been implicated in a variety of cognitive and affective functions in vertebrates (Bisazza et al., 1997b; Miklósi and Andrew, 1999; Kilian et al., 2000). Since presentation of the model to the fish was not followed by attacks and injuries, the fish may have categorised subsequent presentations of the stimulus as innocuous (but still to be avoided), with a shift towards control by the left-sided regions of the brain. A similar phenomenon has been shown to occur in the domesticated chick (Andrew and Brennan, 1983). Jones (1997) notes that fear responses of animals may be altered and integrated according to changes in the perceived potency of the threatening stimulus, and consequently, the intensity of the internal fear state. The cognitive processing and categorisation of startling stimuli as initially threatening, but later innocuous, suggests that fish can experience fear in similar ways to other vertebrate animals. In summary, the cognitive, neurophysiological and behavioural features of fear responses of fish suggest that they have some capacity to consciously experience fear.

\section{Psychological aspects of stress}

When fish are stressed, there is an adrenergic response which results in the liberation of adrenaline and noradrenaline to the blood stream, and a hypothalamo-pituitary-interrenal response, which ultimately results in an increased blood cortisol concentration (Sumpter, 
1997). A number of investigators, however, have also adopted a more encompassing view of stress in fish, by realising that the stress phenomenon is an integrative process that takes into account both the perception of the stressor by fish and the memory of prior experiences in the process that organises the stress response (Barton, 1997). This has prompted several authors to discuss stress in fish not only from a physiological point of view, but from a psychological one as well.

Schreck (1981) was the first to suggest that the psychological component of stress was important in determining the severity of a stress response in fish to physical stressors. Schreck proposed that the psychological well-being of a fish was a factual, tangible phenomenon, that could be elucidated by awareness or positive conditioning experiments. Although very little research has addressed the issue of psychological well-being in fish, the results of such studies clearly demonstrate the psychological component of stress. In one such experiment, Schreck et al. (1995) were able to positively condition chinook salmon (Oncorhynchus tshawytscha) to a stressor (emptying the fish tank until the water just covered the fish's bodies). After conditioning, the fish's physiological stress response (cortisol) to subsequent stressors (transportation) was significantly lowered as compared to controls. In addition, the psychologically hardened fish had a higher rate of survival in a number of challenge tests after the initial transportation stressor (Schreck et al., 1995).

Since many species of farmed fish form social hierarchies, or defend territories (Wedemeyer, 1997), psychological stress in a social context has been more thoroughly studied in fish. In a social context, psychological stress in animals may be conceptualised as having three components (Zayan, 1991). The first consists of a set of negative affective experiences, such as fear. The second component consists of a perceptive process, by which familiar conspecifics are recognised as damaging, and strange conspecifics are viewed as threatening. Fear in fish, and the perceptual process by which conspecifics can be recognised with respect to aggressive ability has been discussed previously. The third component of socially induced psychological stress relates to the cognitive process in which animals can anticipate the presence or actions of stressful conspecifics.

Fish in stable dominance hierarchies may be classified as dominant, subordinate, or intermediate in status. There is evidence to suggest that not only can the subordinate fish in a hierarchical situation anticipate the action of dominant fish, but it can be affected psychologically as well. A number of studies using rainbow trout and Arctic charr have demonstrated that the chronic stress experienced by subordinates is more related to the threat imposed by the presence of the dominant fish, rather than actual aggressive encounters (Winberg and Nilsson, 1993; Winberg and Lepage, 1998; Øverli et al., 1999). This suggests that the experience of a fish being subordinate under captive conditions probably involves an affective state of fear. If an animal is capable of experiencing fear, then the motivational state of that animal could also be expected to be altered. The central serotonergic system of fish seems to have an influence on the motivational state, and consequently, on the behaviour of the fish. The subordinate experience in many vertebrate species, including fish, is associated with an increase in brain serotonergic activity (Winberg and Nilsson, 1993; Winberg et al., 1996). Socially subordinate fish with an increase in brain serotonergic activity are behaviourally inhibited (i.e. less motivated to fight), and show reduced locomotor activity (Øverli et al., 1998, 1999). Interestingly, those findings are similar to the observations and adaptive functions of depression, as described in mammals and other 
vertebrates (Nesse, 2000). Fish also demonstrate increased brain serotonergic activity when they are allowed to view predators (Winberg et al., 1993). The fish telencephalon contains homologous brain nuclei that are observed in tetrapods to mediate psychological stress (e.g. Funada and Hara, 2001). In tetrapods, glucocorticoid induced serotonergic activation occurs in limbic brain regions that are known to mediate social stress and other motivated affective behaviours (Summers et al., 2000). In fish, glucocorticoid receptors can be found in homologous limbic brain regions (Carruth et al., 2000) that also show serotonergic activation when fish are exposed to social stressors (Winberg and Lepage, 1998). The neurobehavioural similarities between fish and other vertebrates with respect to social stress further supports the suggestion that fish have some capacity to experience psychological stress.

\section{General conclusions}

This review of the anatomy, physiology and behaviour of fish suggests that they are more likely to be sentient than not. Therefore, in any fish farming enterprise, the welfare of the fish requires consideration. Animal welfare is discussed and pursued because of ethical concern about the quality of life of animals. Inherent to the concept of animal welfare is that animals have the capacity to suffer, and therefore the quality of life of an animal is greatly determined by how much it may suffer under captive conditions (Duncan and Fraser, 1997). The previous discussion has illustrated that affective states of pain, fear, and psychological stress are likely to be experienced by fish. This implies that like other vertebrates, fish have the capacity to suffer, and that welfare consideration for farmed fish should take these states into account. Therefore, the welfare of farmed fish should include, but range beyond, basic life-support (suitable water conditions and adequate feeding), and should be extended in a manner appropriate for the cognitive abilities they may posses.

The welfare issues relevant for a given species may differ depending on strain variations in cognitive functions and behaviour. Fish species can be divided into three major evolutionary groupings, which have been subject to divergence at an early stage in their evolutionary history (Hildebrand, 1995). There are at least 20,000 species of teleost fish, and the select few that are farmed sometimes show extreme diversity in habits and habitat. Therefore, variability in brain structure and functions are to be expected (Munro and Dodd, 1983; Kotrschal et al., 1998). In addition, different species of farmed fish vary in their stage of domestication (Pottinger and Pickering, 1997). Therefore, the welfare issues when farming catfish, for example, are probably not going to be the same as when farming rainbow trout or relatively non-domesticated Arctic charr. This implies that research to address species-specific welfare concerns is needed.

Aquaculture facilities utilize a number of technologies that need to be examined from the perspective of fish welfare. These include high density culture (Wedemeyer, 1997; Winfree et al., 1998), various feeding strategies (Moutou et al., 1998; Simmons et al., 1999; McCarthy et al., 1999), genomic manipulations (Abrahams and Sutterlin, 1999), handling methods (Grizzle et al., 1992; Bhujel, 2000), transportation (Garcia et al., 2000) and slaughter techniques (Kestin et al., 1991; Marx et al., 1997; Gregory, 1998; Robb et al., 2000). Future research is needed to develop tools that can be used to evaluate the effect of 
these procedures on welfare, and to provide objective information that will help to determine and define the limits of acceptable captive conditions (Chandroo, 2000; Chandroo et al., 2000; Cooke et al., 2000).

\section{Acknowledgements}

We send our thanks to D. Noakes, D. Castle, J. LaMarre and J.F. Leatherland for their constructive reviews of earlier versions of this manuscript. Funding was provided by a grant from the Ontario Ministry of Agriculture and Food to R.D.M.

\section{References}

Abbott, J.C., Dill, L.M., 1985. Patterns of aggressive attack in juvenile steelhead trout (Salmo gairdneri). Can. J. Fish Aquat. Sci 42, 1702-1706.

Abrahams, M.V., Sutterlin, A., 1999. The foraging and antipredator behaviour of growth-enhanced transgenic Atlantic salmon. Anim. Behav. 58, 933-942.

Anadón, R., Rodríguez-Moldes, I., González, A., 2002. Tyrosine hydroxylase immunoreactive neurons in the forebrain of the trout: organization, cellular features and innervation. Brain Res. Bull. 57, 389-392.

Andrew, R.J., Brennan, A., 1983. The lateralization of fear behaviour in the male domestic chick: a developmental study. Anim. Behav. 31, 1166-1176.

Århem, P., Liljenström, H., 1997. On the coevolution of cognition and consciousness. J. Theor. Biol. 187, 601-612. Baars, J.B., 2002. The conscious access hypothesis: origins and recent evidence. Trends Cognit. Sci. 6, 47-52.

Barton, B.A., 1997. Stress in finfish: past, present and future-a historical perspective. In: Iwama, G.K., Pickering, A.D., Sumpter, J.P., Schreck, C.B. (Eds.), Fish Stress and Health in Aquaculture, Society for Experimental Biology, Seminar Series 62. Cambridge University Press, Cambridge, pp. 1-33.

Bernoth, E.M., 1991. Intensive culture of freshwater fish. Deut. Tierärztl. Woch. 98, 312-316.

Besson, J.M., 1999. The neurobiology of pain. Lancet 353, 1610-1615.

Bhujel, R.C., 2000. A review of strategies for the management of Nile tilapia (Oreochromis niloticus) broodfish in seed production systems, especially hapa-based systems. Aquaculture 181, 37-59.

Bisazza, A., De Santi, A., Vallortigara, G., 1999. Laterality and cooperation: mosquitofish move closer to a predator when the companion is on their left side. Anim. Behav. 57, 1145-1149.

Bisazza, A., Pignatti, R., Vallortigara, G., 1997a. Detour tests reveal task- and stimulus-specific behavioural lateralization in mosquitofish (Gambusia holbrooki). Behav. Brain Res. 89, 237-242.

Bisazza, A., Pignatti, R., Vallortigara, G., 1997b. Laterality in detour behaviour: interspecific variation in poeciliid fish. Anim. Behav. 54, 1273-1281.

Bisazza, A., Rogers, L.J., Vallortigara, G., 1998. Origins of cerebral asymmetry: a review of evidence of behavioural and brain lateralization in fishes, reptiles and amphibians. Neurosci. Biobehav. Rev. 22, 411-426.

Bradford Jr., M.R., 1995. Comparative aspects of forebrain organization in the ray-finned fishes: touchstones or not? Brain Behav. Evol. 46, 259-274.

Bradford Jr., M.R., Northcutt, R.G., 1983. Organization of the diencephalon and pretectum of the ray-finned fishes. In: Davis, R.E., Northcutt, R.G. (Eds.), Fish Neurobiology, Vol. 2: Higher Brain Areas and Functions. University of Michigan Press, Ann Arbor, pp. 117-163.

Broom, D.M., 1998. Welfare, stress and the evolution of feelings. Adv. Stud. Behav. 27, 371-403.

Buchanan, J.T., 2001. Contributions of identifiable neurons and neuron classes to lamprey vertebrate neurobiology. Prog. Neurobiol. 63, 441-466.

Butler, A.B., 2000. Topography and topology of the teleost telencephalon: a paradox resolved. Neurosci. Lett. 293, 95-98.

Canfield, J.G., Rose, G.J., 1993. Activation of Mauthner neurons during prey capture. J. Comp. Physiol. A 172, 611-618. 
Cantalupo, C., Bisazza, A., Vallortigara, G., 1995. Lateralization of predator-evasion response in a teleost fish (Girardinus falcatus). Neuropsychologia 33, 1637-1646.

Carruth, L.L., Jones, R.E., Norris, D.O., 2000. Cell density and intracellular translocation of glucocorticoid receptor-immunoreactive neurons in the Kokanee salmon (Oncorhynchus nerka kennerlyi) brain, with an emphasis on the olfactory system. Gen. Comp. Endocrinol. 117, 66-76.

Castro, A., Becerra, M., Anadón, R., Manso, M.J., 2001. Distribution and development of FMRF amide-like immunoreactive neuronal systems in the brain of the brown trout, Salmo trutta fario. J. Comp. Neurol. 440, 43-64.

Cerdá-Reverter, J.M., Zanuy, S., Muñoz-Cueto, J.A., 2001. Cytoarchitectonic study of the brain of a perciform species, the sea bass (Dicentrarchus labrax). I. The telencephalon. J. Morphol. 247, 217-228.

Chandroo, K.P., 2000. Assessing the welfare status of farmed rainbow trout (Oncorhynchus mykiss) with electromyogram telemetry. Master's Thesis, University of Guelph.

Chandroo, K.P., Moccia, R.D., McKinley, R.S., 2000. Utilization of physiological telemetry to monitor behavioural responses of rainbow trout, Oncorhynchus mykiss (Walbaum), to captive culture conditions. Bull. Aquacult. Assoc. Can. 99 (4), 34-36.

Chapman, R.C., Nakamura, Y., 1999. A passion of the soul: an introduction to pain for consciousness researchers. Conscious. Cognit. 8, 391-422.

Chervova, L.S., 1997. Pain sensitivity and behavior of fishes. J. Ichthyol. 37, 98-102.

Christenson, J., Boman, A., Lagerbäck, P., Grillner, S., 1988. The dorsal cell, one class of primary sensory neuron in the lamprey spinal cord. I. Touch, pressure but no nociception-a physiological study. Brain Res. 440, 1-8.

Commons, K.G., Valentino, R.J., 2002. Cellular basis for the effects of substance P in the periaqueductal gray and dorsal raphe nucleus. J. Comp. Neurol. 447, 82-97.

Cooke, S.J., Chandroo, K.P., Beddow, T.A., Moccia, R.D., McKinley, R.S., 2000. Swimming activity and energetic expenditure of captive rainbow trout, Oncorhynchus mykiss (Walbaum), estimated by electromyogram telemetry. Aquacult. Res. 31, 495-505.

Corrêa, S.A.L., Corrêa, F.M.A., Hoffmann, A., 1998. Stereotaxic atlas of the telencephalon of the weekly electric fish Gymnotus carapo. J. Neurosci. Methods 84, 93-100.

Csanyi, V., 1986. Ethological analysis of predator avoidance by the paradise fish (Macropodus opercularis L.): II. Key stimuli in avoidance learning. Anim. Learn. Behav. 14, 101-109.

Cuadrado, M.I., Coveñas, R., Tramu, G., 1994. Distribution of gastrin-releasing peptide/bombesin-like immunoreactivity in the rainbow trout brain. Peptides 15, 1027-1032.

Curtis, S.E., Stricklin, W.R., 1991. The importance of animal cognition in agricultural animal production systems: an overview. J. Anim. Sci. 69, 5001-5007.

Danielson, P.B., Hoversten, M.T., Fitzpatrick, M., Schreck, C., Akil, H., Dores, R.M., 2001. Sturgeon orphanin, a molecular "fossil" that bridges the gap between the opioids and orphanin FQ/nociceptin. J. Biol. Chem. 276, 22114-22119.

Davis, R.E., Kassel, J., 1983. Behavioral functions of the teleostean telencephalon. In: Davis, R.E., Northcutt, R.G. (Eds.), Fish Neurobiology, Vol. 2: Higher Brain Areas and Functions. University of Michigan Press, Ann Arbor, pp. 238-263.

Davis, R.E., Klinger, P.D., 1994. NMDA receptor antagonist MK-801 blocks learning of conditioned stimulus-unconditioned stimulus contiguity but not fear of conditioned stimulus in goldfish (Carassius auratus L.). Behav. Neurosci. 108, 935-940.

Dawkins, M.S., 1993. Through our Eyes Only? The Search for Animal Consciousness. Spektrum Akademischer Verlag, Oxford, $192 \mathrm{pp}$.

Dehaene, S., Naccache, L., 2001. Towards a cognitive neuroscience of consciousness: basic evidence and a workspace framework. Cognition 79, 1-37.

Dennett, D., 2001. Are we explaining consciousness yet? Cognition 79, 221-237.

Dickinson, A., Balleine, B., 1994. Motivational control of goal-directed action. Anim. Learn. Behav. 22, 1-18.

Dietrich, M., Hofmann, M.H., Bleckmann, H., 2002. Effects of dopaminergic drugs and telencephalic ablation on eye movements in the goldfish, Carassius auratus. Brain Res. Bull. 57, 393-395.

Dol, M., Kasanmoentalib, S., Lijmbach, S., Rivas, E., Van den Bos, R.E., 1997. Animal Consciousness and Animal Ethics. Perspectives from the Netherlands. Van Gorcum, Assen, The Netherlands, 249 pp.

Domenici, P., Blake, R.W., 1997. The kinematics and performance of fish fast-start swimming. J. Exp. Biol. 200, 1165-1178. 
Doutrelant, C., McGregor, P.K., 2000. Eavesdropping and mate choice in female Fighting fish. Behaviour 137, $1655-1669$.

Duncan, I.J.H., 1996. Animal welfare defined in terms of feelings. Acta Agric. Scand. A Suppl. 27, $29-35$.

Duncan, I.J.H., 2002. Poultry welfare: science or subjectivity? Br. Poult. Sci. 43, 643-652.

Duncan, I.J.H., Fraser, D., 1997. Understanding animal welfare. In: Appleby, M.C., Hughes, B.O. (Eds.), Animal Welfare, CAB International. University Press, Cambridge, pp. 19-31.

Duncan, I.J.H., Petherick, J.C., 1991. The implications of cognitive processes for animal welfare. J. Anim. Sci. $69,5017-5022$

Eaton, R.C., Lavender, W.A., Wieland, C.M., 1981. Identification of Mauthner-initiated response in goldfish: evidence from simultaneous cinematography and electrophysiology. J. Comp. Physiol. 144, 521-531.

Eaton, R.C., Lavender, W.A., Wieland, C.M., 1982. Alternative neural pathways initiate fast-start responses following lesions of the Mauthner neuron in goldfish. J. Comp. Physiol. 145, 485-496.

Eaton, R.C., Lee, R.K.K., Foreman, M.B., 2001. The Mauthner cell and other identified neurons of the brainstem escape network of fish. Prog. Neurobiol. 63, 467-485.

Eaton, R.C., Nissanov, J., 1985. A review of Mauthner-initiated escape behaviour and its possible role in hatching in the immature zebrafish, Brachydanio rerio. Environ. Biol. Fish. 12, 265-279.

Ebbesson, S.O.E., Hodde, K.C., 1981. Ascending spinal systems in the nurse shark, Ginglymostoma cirratum. Cell Tissue Res. 216, 313-331.

Echteler, S.M., Saidel, W.M., 1981. Forebrain connections in the goldfish support telencephalic homologies with land vertebrates. Science 212, 683-684.

Edelman, G.M., Tononi, G., 2000. Universe of Consciousness. Basic Books, United States of America, 274 pp.

Ehrensing, R.H., Michell, G.F., Kastin, A.J., 1982. Similar antagonism of morphine analgesia by MIF-1 and naloxone in Carassius auratus. Pharmacol. Biochem. Behav. 17, 757-761.

Eichenbaum, H., 1997. Declarative memory: insights from cognitive neurobiology. Annu. Rev. Psychol. 48, 547572.

Facchin, L., Bisazza, A., Vallortigara, G., 1999. What causes lateralization of detour behavior in fish? Evidence for asymmetries in eye use. Behav. Brain Res. 103, 229-234.

Fanselow, M.S., Lester, L.S., 1988. A functional behavioristic approach to aversively motivated behavior: predatory imminence as a determinant of the topography of defensive behavior. In: Bolles, R.C., Beecher, M.D. (Eds.), Evolution and Learning. Lawrence Erlbaum, New Jersey, pp. 185-212.

FAO, 2000. The State of World Fisheries and Aquaculture. Food and Agriculture Organization of the United Nations.

FAWC, 1996. Report on the Welfare of Farmed Fish. Farm Animal Welfare Council, Surrey, England, 52 pp.

Fibiger, H.C., Phillips, A.G., 1986. Reward, motivation, cognition: psychobiology of mesotelencephalic dopamine systems. In: Mountcastle, V.B., Bloom, F.E., Geiger, S.R. (Eds.), Handbook of Physiology, Vol. 4: The Nervous System. American Physiological Society, Bethesda, MD, pp. 647-675.

Finger, T.E., 2000. Ascending spinal systems in the fish, Prionotus carolinus. J. Comp. Neurol. 422, $106-122$.

Finger, T.E., Rovainen, C.M., 1982. Spinal and medullary dorsal cell axons in the trigeminal nerve in lampreys. Brain Res. 240, 331-333.

Folgueira, M., Huesa, G., Anadón, R., Yáñez, J., 2002. The nucleus sublomerulosus of the trout hypothalamus is a link between chemosensory and visual systems: a Dil study. Brain Res. Bull. 57, 427-430.

Fox, H.E., White, S.A., Kao, M.H.F., Fernald, R.D., 1997. Stress and dominance in a social fish. J. Neurosci. 17, 6463-6469.

Fraser, D., Duncan, I.J.H., 1998. 'Pleasures', 'pains' and animal welfare: toward a natural history of affect. Anim. Welfare 7, 383-396.

Fraser, D., Weary, D.M., Pajor, E.A., Milligan, B.N., 1997. A scientific conception of animal welfare that reflects ethical concerns. Anim. Welfare 6, 187-205.

Funada, M., Hara, C., 2001. Differential effects of psychological stress on activation of the 5-hydroxytryptamineand dopamine-containing neurons in the brain of freely moving rats. Brain Res. 901, 247-251.

Furevik, D.M., Bjordal, Å., Huse, I., Ferno, A., 1993. Surface activity of Atlantic salmon (Salmo salar L.) in net pens. Aquaculture 110, 119-128.

Garcia, L.M.B., Hilomen-Garcia, G.V., Emata, A.C., 2000. Survival of captive milkfish Chanos chanos Forsskal broodstock subjected to handling and transport. Aquacult. Res. 31, 575-583. 
Goodson, J.L., Bass, A.H., 2002. Vocal-acoustic circuitry and descending vocal pathways in teleost fish: convergence with terrestrial vertebrates reveals conserved traits. J. Comp. Neurol. 448, 298-322.

Goping, G., Pollard, H.B., Adeyemo, O.M., Kuijpers, G.A.J., 1995. Effect of MPTP on dopaminergic neurons in the goldfish brain: a light and electron microscope study. Brain Res. 687, 35-52.

Gregory, N.G., 1998. Animal Welfare and Meat Science. CABI Publishing, Wallingford, UK, pp. 195-212.

Gregory, N., 1999. Do fish feel pain? Surveillance 26, 8-10.

Griffin, D.R., 1998. From cognition to consciousness. Anim. Cognit. 1, 3-16.

Grizzle, J.M., Chen, J., Williams, J.C., Spano, J.S., 1992. Skin injuries and serum enzyme activities of channel catfish (Ictalurus punctatus) harvested by fish pumps. Aquaculture 107, 333-346.

Hall, D., Suboski, D., 1995. Visual and olfactory stimuli in learned release of alarm reactions by zebra danio fish (Brachydanio rerio). Neurobiol. Learn. Mem. 63, 229-240.

Heyes, C.M., 1993. Imitation, culture and cognition. Anim. Behav. 46, 999-1010.

Hildebrand, M., 1995. Analysis of Vertebrate Structure, 4th ed. John Wiley \& Sons, New York, 672 pp.

Höjesjo, J., Johnsson, J., Petersson, E., Järvi, T., 1998. The importance of being familiar: individual recognition and social behavior in sea trout (Salmo trutta). Behav. Ecol. 9, 445-451.

Höglund, E., Balm, P.H., Winberg, S., 2000. Skin darkening, a potential social signal in subordinate Arctic charr (Salvelinus alpinus): the regulatory role of brain monoamines and pro-opiomelanocortin-derived peptides. J. Exp. Biol. 203, 1711-1721.

Humphrey, N., 1992. A History of the Mind: Evolution and the Birth of Consciousness. Springer-Verlag, New York.

Ide, L.M., Hoffmann, A., 2002. Stressful and behavioral conditions that affect reversible cardiac arrest in the Nile tilapia, Oreochromis niloticus (Teleostei). Physiol. Behav. 75, 119-126.

Ito, H., Kishida, R., 1978. Telencephalic afferent neurons identified by the retrograde HRP method in the carp diencephalon. Brain Res. 149, 211-215.

Ito, H., Murakami, T., Fukuoka, T., Kishida, R., 1986. Thalamic fiber connections in a teleost (Sebastiscus marmoratus): visual somatosensory, octavolateral, and cerebellar relay region to the telencephalon. J. Comp. Neurol. 250, 215-227.

Jansen, G.A., Green, N.M., 1970. Morphine metabolism and morphine tolerance in goldfish. Anesthesiology 32, $231-235$.

Johnsson, J.I., 1997. Individual recognition affects aggression and dominance relations in rainbow trout, Oncorhynchus mykiss. Ethology 103, 267-282.

Johnsson, J.I., Åkerman, A., 1998. Watch and learn: preview of the fighting ability of opponents alter contest behaviour in rainbow trout. Anim. Behav. 56, 771-776.

Jones, R.B., 1997. Fear and distress. In: Appleby, M.C., Hughes, B.O. (Eds.), Animal Welfare, CAB International. University Press, Cambridge, pp. 75-87.

Kálmán, M., 1998. Astroglial architecture of the carp (Cyprinus carpio) brain as revealed by immunohistochemical staining against glial fibrillary acidic protein (GFAP). Anat. Embryol. 198, 409-433.

Kestin, S.C., 1994. Pain and Stress in Fish. Royal Society for the Prevention of Cruelty to Animals. RSPCA, Horsham, Sussex.

Kestin, S.C., Wotton, S.B., Gregory, N.G., 1991. Effect of slaughter by removal from water on visual evoked activity in the brain and reflex movement of rainbow trout (Oncorhynchus mykiss). Vet. Rec. 128, 443-446.

Kevetter, G.A., Willis, W.D., 1984. Collateralization in the spinothalamic tract: new methodology to support or deny phylogenetic theories. Brain Res. Rev. 7, 1-14.

Kieffer, J.D., Colgan, P.W., 1992. The role of learning in fish behaviour. Rev. Fish Biol. Fisher. 2, $125-143$.

Kilian, A., von Fersen, L., Güntürkün, O., 2000. Lateralization of visuospatial processing in the bottlenose dolphin (Tursiops truncatus). Behav. Brain Res. 116, 211-215.

Kitchell, R.L., Guinan, M.J., 1990. The nature of pain in animals. In: Rollin, B.E., Kesel, M.L. (Eds.), The Experimental Animal in Biomedical Research, vol. 1. CRC Press, Boca Raton, pp. 185-204.

Kotrschal, K., van Staaden, M.J., Huber, R., 1998. Fish brains: evolution and environmental relationships. Rev. Fish Biol. Fisher. 8, 373-408.

Kötter, R., Meyer, N., 1992. The limbic system: a review of its empirical foundation. Behav. Brain Res. 52, $105-127$.

Laberge, F., Hara, T.J., 2001. Neurobiology of fish olfaction: a review. Brain Res. Rev. 36, 46-59.

Lee, L.T., Bullock, T.H., 1984. Sensory representation in the cerebellum of the catfish. Neuroscience 13, $157-169$. 
LeDoux, J.E., 2000. Emotion circuits in the brain. Annu. Rev. Neurosci. 23, 155-184.

Le Moal, M., Simon, H., 1991. Mesocorticolimbic dopaminergic network: functional and regulatory roles. Physiol. Rev. 71, 155-234.

Lett, B.T., Grant, V.L., 1989. The hedonic effects of amphetamine and pentobarbital in goldfish. Pharmacol. Biochem. Behav. 32, 355-356.

Lindahl, B.I.B., 1997. Consciousness and biological evolution. J. Theor. Biol. 187, 613-629.

López, C.J., Broglio, C., Rodríguez, F., Thinus-Blanc, C., Salas, C., 2000a. Reversal learning deficit in a spatial task but not in a cued one after telencephalic ablation in goldfish. Behav. Brain Res. 109, 91-98.

López, J.C., Bingman, V.P., Rodríguez, F., Gómez, Y., Salas, C., 2000b. Dissociation of place and cue learning by telencephalic ablation in goldfish. Behav. Neurosci. 114, 687-699.

Losey Jr., G.S., Margules, L., 1974. Cleaning symbiosis provides a positive reinforcer for fish. Science 184, 179-180.

Lymbery, P., 1992. The welfare of farmed fish. In: Compassion in World Farming, Hants. Cattleshall Printing Services, $20 \mathrm{pp}$.

Maren, S., 2001. Neurobiology of pavlovian fear conditioning. Ann. Rev. Neurosci. 24, 897-931.

Martin, A.R., Wickelgren, W.O., 1971. Sensory cells in the spinal cord of the sea lamprey. J. Physiol. 212, 65-83.

Marx, H., Brunner, B., Weinzierl, W., Hoffmann, R., Stolle, A., 1997. Methods of stunning freshwater fish: impact on meat quality and aspects of animal welfare. Eur. Food Res. Technol. 204, 282-286.

Matthews, G., Wickelgren, W.O., 1978. Trigeminal sensory neurons of the sea lamprey. J. Comp. Physiol. 123, 329-333.

Mattioli, R., Aguilar, C., Vasconcelos, L., 1995. Reinforcing properties of the neuropeptide substance P in Carassius auratus: evidence of dopaminergic system involvement. Pharmacol. Biochem. Behav. 50, 77-81.

Mattioli, R., Santangelo, E.M., Costa, A.C.C., Vasconcelos, L., 1997. Substance P facilitates memory in goldfish in an appetitively motivated learning task. Behav. Brain Res. 85, 117-120.

McCarthy, I.D., Gair, D.J., Houlihan, D.F., 1999. Feeding rank and dominance in Tilapia rendalli under defensible and indefensible patterns of food distribution. J. Fish Biol. 55, 854-867.

McGregor, P.K., Peak, T.M., Lampe, H.M., 2001. Fighting fish Betta splendens extract relative information from apparent interactions: what happens when what you see is not what you get. Anim. Behav. 62, 1059-1065.

Miklósi, Á., Andrew, R.J., 1999. Right eye use associated with decision to bite in zebrafish. Behav. Brain Res. 105, 199-205.

Mok, E.Y.M., Munro, A.D., 1998. Effects of dopaminergic drugs on locomotor activity in teleost fish of the genus Oreochromis (Cichlidae): involvement of the telencephalon. Physiol. Behav. 64, 227-234.

Morris, M.R., Gass, L., Ryan, M.J., 1995. Assessment and individual recognition of opponents in the pygmy swordtails Xiphophorus nigrensis and X. multilineatus. Behav. Ecol. Sociobiol. 37, 303-310.

Moutou, K.A., McCarthy, I.D., Houlihan, D.F., 1998. The effect of ration level and social rank on the development of fin damage in juvenile rainbow trout. J. Fish Biol. 52, 756-770.

Munro, A.D., 1986. The effects of apomorphine, D-amphetamine and chloropromazine on the aggressiveness of isolated Aequidens pulcher (Teleostei Cichlidae). Psychopharmacology 88, 124-128.

Munro, A.D., Dodd, J.M., 1983. Forebrain of fishes: neuroendocrine control mechanisms. In: Nisticò, G., Bolis, L. (Eds.), Progress in Nonmammalian Brain Research, vol. III. CRC Press, Florida, pp. 2-78.

Murakami, T., Ito, H., 1985. Long ascending projections of the spinal dorsal horn in a teleost, Sebastiscus marmoratus. Brain Res. 346, 168-170.

Needham, E.A., Lehman, H., 1991. Farming salmon ethically. J. Agric. Environ. Ethics 14, 78-81.

Nesse, R.M., 2000. Is depression an adaptation? Arch. Gen. Psychiat. 57, 14-20.

Neukirch, M., 1994. Legitimate aspects relevant to animal protection on killing fish. Deut. Tierärztl. Woch. 101, 316-319.

Ng, T.B., Chan, T.H., 1990. Adrenocorticotropin-like and opiate-like materials in the brain of the red grouper Epinephelus akaara (Teleostei: serranidae). Comp. Biochem. Physiol. C 95, 159-162.

Nieuwenhuys, R., 1982. An overview of the organization of the brain of actinopterygian fishes. Am. Zool. 22, 287-310.

Nieuwenhuys, R., Pouwels, E., 1983. The brain stem of Actinopterygian fishes. In: Northcutt, R.G., Davis, R.E. (Eds.), Fish Neurobiology, Vol. 1: Brain Stem and Sense Organs. University of Michigan Press, Ann Arbor, pp. 25-87. 
O’Connor, K.I., Metcalfe, N.B., Taylor, A.C., 1999. Does darkening signal submission in territorial contests between juvenile Atlantic salmon, Salmo salar? Anim. Behav. 58, 1269-1276.

O'Connor, K.I., Metcalfe, N.B., Taylor, A.C., 2000. Familiarity influences body darkening in territorial disputes between juvenile salmon. Anim. Behav. 59, 1095-1101.

Ohnishi, K., 1997. Effects of telencephalic ablation on short-term memory and attention in goldfish. Behav. Brain Res. 86, 191-199.

Oliveira, R.F., McGregor, P.K., Latruffe, C., 1998. Know thine enemy: fighting fish gather information from observing conspecific interactions. Proc. R. Soc. Lond. B Biol. Sci. 265, 1045-1049.

Ono, T., Nishijo, H., Nishino, H., 2000. Functional role of the limbic system and basal ganglia in motivated behaviours. J. Neurol. 247 (Suppl. V), V23-V32.

Overmier, J.B., Hollis, K.L., 1983. The teleostean telencephalon in learning. In: Davis, R.E., Northcutt, R.G. (Eds.), Fish Neurobiology, Vol. 2: Higher Brain Areas and Functions. University of Michigan Press, Ann Arbor, pp. 265-283.

Overmier, J.B., Hollis, K.L., 1990. Fish in the think tank: learning, memory and integrated behaviour. In: Kesner, R.P., Olson, D.S. (Eds.), Neurobiology of Comparative Cognition. Lawrence Erlbaum, Hillsdales, NJ, pp. 205-236.

Øverli, Ø., Harris, C.A., Winberg, S., 1999. Short-term effects of fights for social dominance and the establishment of dominant-subordinate relationships on brain monoamines and cortisol in raibow trout. Brain Behav. Evol. 54, 263-275.

Øverli, Ø., Winberg, S., Damsgård, B., Jobling, M., 1998. Food intake and spontaneous swimming activity in Arctic charr (Salvelinus alpinus): role of brain serotonergic activity and social interactions. Can. J. Zool. 76, 1366-1370.

Peters, G., 1990. Problems concerning animal protection laws in connection with mass culture of fishes. Deut. Tierärztl. 97, 157-160.

Petrovich, G.D., Canteras, N.S., Swanson, L.W., 2001. Combinatorial amygdalar inputs to hippocampal domains and hypothalmic behavior systems. Brain Res. Rev. 38, 247-289.

Piront, M., Schmidt, R., 1988. Inhibition of long-term memory formation by anti-ependymin antisera after active shock-avoidance learning in goldfish. Brain Res. 442, 53-62.

Pitcher, T.J., 1993. Behaviour of Teleost Fishes, 2nd ed. Chapman \& Hall, London.

Pollard, H.B., Kuijpers, G.A., Adeyemo, O.M., Youdim, M.B.H., Goping, G., 1996. The MPTP-induced A. pulcherian syndrome in the goldfish is associated with major cell destruction in the forebrain and subtle changes in the optic tectum. Exp. Neurol. 142, 170-178.

Portavella, M., Vargas, J.P., Torres, B., Salas, C., 2002. The effects of telencephalic pallial lesions on spatial, temporal, and emotional learning in goldfish. Brain Res. Bull. 57, 397-399.

Porteros, A., García-Isidoro, M., Barrallo, A., González-Sarmiento, R., Rodríguez, R.E., 1999. Expression of ZFOR1, $\delta$-opioid receptor, in the central nervous system of the zebrafish (Danio rerio). J. Comp. Neurol. 412, $429-438$.

Pottinger, T.G., Pickering, A.D., 1997. Genetic basis to the stress response: selective breeding for stress-tolerant fish. In: Iwama, G.K., Pickering, A.D., Sumpter, J.P., Schreck, C.B. (Eds.), Fish Stress and Health in Aquaculture, Society for Experimental Biology, Seminar Series 62. Cambridge University Press, Cambridge, pp. 171-193.

Prechtl, J.C., von der Emde, G., Wolfart, J., Karamürsel, S., Akoev, G.N., Andrianov, Y.N., Bullock, T.H., 1998. Sensory processing in the pallium of a mormyrid fish. J. Neurosci. 18, 7381-7393.

Puzdrowski, R.L., 1988. Afferent projections of the trigeminal nerve in the goldfish, Carassius auratus. J. Morphol. 198, 131-147.

Rehnberg, B.G., Bates, E.H., Smith, R.J.F., Sloley, B.D., Richardson, J.S., 1989. Brain benzodiazepine receptors in fathead minnows and the behavioural response to alarm pheromone. Pharmacol. Biochem. Behav. 33, 435-442.

Riedel, G., 1998. Long-term habituation to spatial novelty in blind cave fish (Astyanax hubbsi): role of the telencephalon and its subregions. Learn. Mem. 4, 451-461.

Rink, E., Wullimann, M.F., 2001. The teleostean (zebrafish) dopaminergic system ascending to the subpallium (striatum) is located in the basal diencephalon (posterior tuberculum). Brain Res. 889, 316-330.

Robb, D.H.F., Wotton, S.B., McKinstry, J.L., Sørensen, N.K., Kestin, S.C., 2000. Commercial slaughter methods used on Atlantic salmon: determination of the onset of brain failure by electroencephalography. Vet. Rec. 147, 298-303. 
Roberts, B.L., 1992. Neural mechanisms underlying escape behaviour in fishes. Rev. Fish Biol. Fisher. 2, $243-266$.

Rodríguez, F., López, J.C., Vargas, J.P., Broglio, C., Gómez, Y., Salas, C., 2002a. Spatial memory and hippocampal pallium through vertebrate evolution: insights from reptiles and teleost fish. Brain Res. Bull. 57, 499-503.

Rodríguez, F., López, J.C., Vargas, J.P., Gómez, Y., Broglio, C., Salas, C., 2002b. Conservation of spatial memory function in the pallial forebrain of reptiles and ray-finned fishes. J. Neurosci. 22, 2894-2903.

Rolls, E.T., 2000. Précis of the brain and emotion. Behav. Brain Sci. 23, 177-234.

Romanes, G.J., 1884 (reprinted 1969). Mental Evolution in Animals. AMS Press, New York, 411 pp.

Ronan, M., Northcutt, R.G., 1990. Projections ascending from the spinal cord to the brain in petromyzontid and myxinoid agnathans. J. Comp. Neurol. 291, 491-508.

Rooney, D.J., Laming, P.R., 1988. Effects of telencephalic ablation on habituation of arousal responses, within and between daily training sessions in goldfish. Behav. Neural. Biol. 49, 83-96.

Rose, J.D., 2002. The neurobehavioral nature of fishes and the question of awareness and pain. Rev. Fish. Sci. 10, $1-38$.

Rose, M., Adams, D., 1989. Evidence for pain and suffering in other animals. In: Langley, G. (Ed.), Animal Experimentation: The Consensus Changes. Chapman \& Hall, New York, pp. 42-71.

Rovainen, C.M., Yan, Q., 1985. Sensory responses of dorsal cells in the lamprey brain. J. Comp. Physiol. A 156, 181-183.

Saidel, W.M., Marquez-Houston, K., Butler, A.B., 2001. Identification of visual pallial telencephalon in the goldfish, Carassius auratus: a combined cytochrome oxidase and electrophysiological study. Brain Res. 919, 82-93.

Salas, C., Broglio, C., Rodríguez, F., López, J.C., Portavella, M., Torres, B., 1996a. Telencephalic ablation in goldfish impairs performance in a 'spatial constancy' problem but not in a cued one. Behav. Brain Res. 79, 193-200.

Salas, C., Rodríguez, F., Vargas, J.P., Durán, E., Torres, B., 1996b. Spatial learning and memory deficits after telencephalic ablation in goldfish trained in place and turn maze procedures. Behav. Neurosci. 110, 965-980.

Salzen, E.A., 1998. Emotion and self-awareness. Appl. Anim. Behav. Sci. 57, 299-313.

Santangelo, E.M., Morato, S., Mattioli, R., 2001. Facilitatory effect of substance P on learning and memory in the inhibitory avoidance test for goldfish. Neurosci. Lett. 303, 137-139.

Savage, G., 1980. The fish telencephalon and its relation to learning. In: Ebbesson, S.O.E. (Ed.), Comparative Neurology of the Telencephalon. Plenum Press, New York, pp. 129-174.

Sawai, N., Yamamoto, N., Yoshimoto, M., Ito, H., 2000. Fiber connections of the corpus mamillare in a percomorph teleost, tilapia Oreochromis niloticus. Brain Behav. Evol. 55, 1-13.

Schreck, C.B., 1981. Stress and compensation in teleostean fishes: response to social and physical factors. In: Pickering, A.D. (Ed.), Stress and Fish. Academic Press, New York, pp. 295-321.

Schreck, C.B., Jonsson, L., Feist, G., Reno, P., 1995. Conditioning improves performance of juvenile chinook salmon, Oncorhynchus tshawytscha, to transportation stress. Aquaculture 135, 99-110.

Searle, J.R., 2000. Consciousness. Ann. Rev. Neurosci. 23, 557-578.

Shettleworth, S.J., 2001. Animal cognition and animal behaviour. Anim. Behav. 61, 277-286.

Simmons, L., Moccia, R.D., Bureau, D.P., Sivak, J.G., Herbert, K., 1999. Dietary methionine requirement of juvenile Arctic charr Salvelinus alpinus (L.). Aquacult. Nutr. 5, 93-100.

Smith, R.J.F., 1992. Alarm signals in fishes. Rev. Fish Biol. Fisher. 2, 33-63.

Sneddon, L.U., 2002. Anatomical and electrophysiological analysis of the trigeminal nerve in a teleost fish, Oncorhynchus mykiss. Neurosci. Lett. 319, 167-171.

Sneddon, L.U., 2003. The evidence for pain in fish: the use of morphine as an analgesic. Appl. Anim. Behav. Sci. $83,153-162$.

Sneddon, L.U., Braithwaite, V.A., Gentle, M.J., 2003. Do fishes have nociceptors? Evidence for the evolution of a vertebrate sensory system. Proc. R. Soc. Lond. B270, 1115-1121.

Spedding, C., 2000. Animal Welfare. Earthscan Publications Ltd., London, pp. 31-44.

Stoskopf, M.K., 1994. Pain and analgesia in birds, reptiles, amphibians, and fish. Invest. Opth. Vis. Sci. 35 , 775-780.

Striedter, G.F., 1997. The telencephalon of tetrapods in evolution. Brain Behav. Evol. 49, 179-213.

Summers, C.H., Larson, E.T., Ronan, P.J., Hofmann, P.M., Emerson, A.J., Renner, K.J., 2000. Serotonergic responses to corticosterone and testosterone in the limbic system. Gen. Comp. Endocrinol. 117, 151-159. 
Sumpter, J.P., 1997. The endocrinology of stress. In: Iwama, G.K., Pickering, A.D., Sumpter, J.P., Schreck, C.B. (Eds.), Fish Stress and Health in Aquaculture, Society for Experimental Biology, Seminar Series 62. Cambridge University Press, Cambridge, pp. 95-118.

Tononi, G., Edelman, G.M., 1998. Consciousness and complexity. Science 282, 1846-1851.

Topál, J., Csányi, V., 1999. Interactive learning in the paradise fish (Macopodus opercularis): an ethological interpretation of the second-order conditioning paradigm. Anim. Cognit. 2, 197-206.

Ullström, M., Parker, D., Svensson, E., Grillner, S., 1999. Neuropeptide-mediated facilitation and inhibition of sensory inputs and spinal cord reflexes in the lamprey. J. Neurophysiol. 81, 1730-1740.

Vargas, J.P., Rodrîguez, F., López, J.C., Arias, J.L., Salas, C., 2000. Spatial learning-induced increase in the argyrophilic nucleolar organizer region of dorsolateral telencephalic neurons in goldfish. Brain Res. 865, 77-84.

Vecino, E., Piñuela, C., Arévalo, R., Lara, J., Alonso, J.R., Aijón, J., 1992. Distribution of enkaphalin-like immunoreactivity in the central nervous system of the rainbow trout: an immunocyochemical study. J. Anat. $180,435-453$.

Vonderschen, K., Bleckmann, H., Hofmann, M.H., 2002. A direct projection from the cerebellum to the telencephalon in the goldfish, Carassius auratus. Neurosci. Lett. 320, 37-40.

Webb, P.W., 1986. Effect of body form and response threshold on the vulnerability of four species of teleost prey attacked by largemouth bass (Micropterus salmoides). Can. J. Fish. Aquat. Sci. 43, 763-771.

Wedemeyer, G.A., 1997. Effects of rearing conditions on the health and physiological quality of fish in intensive culture. In: Iwama, G.K., Pickering, A.D., Sumpter, J.P., Schreck, C.B. (Eds.), Fish Stress and Health in Aquaculture, Society for Experimental Biology, Seminar Series 62. Cambridge University Press, Cambridge, pp. 35-71.

Weld, M.M., Maler, L., 1992. Substance P-like immunoreactivity in the brain of the gymnotiform fish Apteronotus leptorhynchus: presence of sex differences. J. Chem. Neuroanat. 5, 107-129.

Wicht, H., Northcutt, R.G., 1998. Telencephalic connections in the pacific hagfish (Eptatretus stouti), with special reference to the thalamopallial system. J. Comp. Neurol. 395, 245-260.

Willis, W.D., Westlund, K.N., 1997. Neuroanatomy of the pain system and of the pathways that modulate pain. J. Clin. Neurophysiol. 14, 2-31.

Winberg, S., Lepage, O., 1998. Elevation of brain 5-HT activity, POMC expression, and plasma cortisol in socially subordinate rainbow trout. Am. J. Physiol. 274, R645-R654.

Winberg, S., Myrberg Jr., A.A., Nilsson, G.E., 1993. Predator exposure alters brain serotonin metabolism in bicolour damselfish. Neuroreport 4, 399-402.

Winberg, S., Myrberg Jr., A.A., Nilsson, G.E., 1996. Agonistic interactions affect brain serotonergic activity in an Acanthopterygiian fish: the bicolor damselfish (Pomacentrus partitus). Brain Behav. Evol. 48, 213-220.

Winberg, S., Nilsson, G.E., 1993. Time course of changes in brain serotonergic activity and brain tryptophan levels in dominant and subordinate juvenile arctic charr. J. Exp. Biol. 179, 181-195.

Winfree, R.A., Kindschi, G.A., Shaw, H.T., 1998. Elevated water temperature, crowding, and food deprivation accelerate fin erosion in juvenile steelhead. Prog. Fish. Cult. 60, 192-199.

Wisenden, B.D., Smith, R.J.F., 1998. A re-evaluation of the effect of shoalmate familiarity on the proliferation of alarm substance cells in Ostariophysan fishes. J. Fish Biol. 53, 841-846.

Wood-Gush, D.G.M., Dawkins, M.S., Ewbank, R., 1981. Self-Awareness in Domesticated Animals. Universities Federation for Animal Welfare, Potters Bar, England.

Wullimann, M.F., Rink, E., 2002. The teleostean forebrain: a comparative and developmental view based on early proliferation, Pax6 activity and catecholaminergic organization. Brain Res. Bull. 57, 363-370.

Yañez, J., Anadón, R., 1996. Afferent and efferent connections of the habenula in the rainbow trout (Oncorhynchus mykiss): an indocarbocyanine dye (DiI) study. J. Comp. Neurol. 372, 529-543.

Yoshimoto, M., Albert, J.S., Sawai, N., Shimizu, M., Yamamoto, N., Ito, H., 1998. Telencephalic ascending gustatory system in a cichlid fish, Oreochromis (Tilapia) niloticus. J. Comp. Neurol. 392, 209-226.

Zayan, R., 1991. The specificity of social stress. Behav. Process. 25, 81-93.

Zerbolio, D.J., Royalty, J.L., 1983. Matching and oddity conditional discrimination in the goldfish as avoidance responses: evidence for conceptual avoidance learning. Anim. Learn. Behav. 11, 341-348.

Zieglgänsberger, W., 1986. Central control of nociception. In: Mountcastle, V.B., Bloom, F.E., Geiger, S.R. (Eds.), Handbook of Physiology, Vol. 4: The Nervous System. American Physiological Society, Bethesda, MD, pp. 581-645. 
Zimmermann, M., 1986. Behavioural investigations of pain in animals. In: Duncan, I.J.H., Molony, V. (Eds.), Assessing Pain in Farm Animals. Commission of the European Communities, Luxembourg, pp. 16-27.

Zottoli, S.J., Newman, B.C., Rieff, H.I., Winters, D.C., 1999. Decrease in occurrence of fast startle responses after selective Mauthner cell ablation in goldfish (Carassius auratus). J. Comp. Physiol. A 184, 207-218.

Zupanc, G.K.H., 1997. The preglomerular nucleus of gymnotiform fish: relay station for conveying information between telencephalon and diencephalon. Brain Res. 761, 179-191. 